\title{
SUCCESSFUL HEART TRANSPLANTATION IN A PATIENT WITH HEART FAILURE AND PERSISTING Q FEVER.
}

\author{
Marcel van t Veer $^{1}$, Luuk Otterspoor ${ }^{1}$, Marieke de Regt ${ }^{2}$, Jola Evens ${ }^{3}$, Kathinka Peels ${ }^{1}$, \\ and Nicolaas de Jonge ${ }^{3}$ \\ ${ }^{1}$ Catharina Hospital \\ ${ }^{2}$ Onze Lieve Vrouwe Gasthuis \\ ${ }^{3}$ University Medical Center Utrecht
}

May 6, 2020

\begin{abstract}
Active infection is generally considered a contraindication for heart transplantation. The rare combination of a patient with an active Coxiella burnetii infection and a congenital corrected transposition of the great arteries requiring heart transplantation imposes challenging treatment decisions. We present a case of a patient with end stage heart failure requiring heart transplantation who developed chronic Q-fever and endocarditis.
\end{abstract}

\section{Hosted file}

Q-fever HTX case J Card Surg.docx available at https://authorea.com/users/317136/articles/ 448527-successful-heart-transplantation-in-a-patient-with-heart-failure-and-persistingq-fever 